\title{
LA RECEPCIÓN DE LA TEORÍA DE LOS SISTEMAS DE LUHMANN EN LA JURISPRUDENCIA CONSTITUCIONAL COLOMBIANA*
}

\author{
Paola Ruiz Manotas" \\ Luis Fernando Bermeo***
}

Fecha de recepción: 16 de febrero de 2017

Fecha de evaluación: 8 de abril de 2018

Fecha de aprobación: 2 de mayo de 2018

Artículo de reflexión

DOI:

Forma de citación: Ruíz, Manotas, P., \& Bermeo, L. F. (2018). La recepción de la teoría de los sistemas de Luhmann en la jurisprudencia constitucional colombiana. Revista Prolegómenos Derechos y Valores, 21(42), 161-175, DOI:

\section{RESUMEN}

Este texto presenta algunas consideraciones sobre la influencia que ha tenido la teoría de los sistemas de Luhmann en las decisiones de la Corte Constitucional Colombiana desde sus inicios. Encontraremos una mención general sobre los conceptos básicos de la teoría luhmanniana, sobre la interrelación de los sistemas sociales Derecho, Política y Moral y sobre algunas críticas que podrían plantearse desde Luhmann hacia el positivismo jurídico. Se hizo un estudio de la jurisprudencia de la Corte Constitucional Colombiana desde su creación hasta la fecha de la investigación, analizando en cuáles de estas el tribunal constitucional utilizó la teoría luhmanniana para sustentar su fallo y de qué forma lo hizo, encontrando que solo en tres sentencias fue citada la teoría de Luhmann, lo que indica una precariedad en cuanto a su consideración como una teoría "aceptada" por quienes ejercen el derecho en Colombia.

\section{Palabras clave:}

Autopoiesis; código binario; derecho; moral; política; sistemas.

\footnotetext{
Artículo producto de una investigación realizada al marco del seminario de Filosofía del Derecho II dentro de la Maestría en Derecho de la Universidad del Norte.

* Abogada de la Universidad del Norte. Magister en Derecho con énfasis en investigación de la Universidad del Norte. Profesional Especializado grado 33 de la Jurisdicción Especial para la Paz. Investigadora independiente. Correo electrónico: pmrm30@hotmail.com

** Abogado de la Universidad de Cartagena. Magister en Derecho con énfasis en investigación de la Universidad del Norte. Profesor de la Fundación Universitaria Tecnológico Comfenalco (Cartagena - Colombia). Investigador del Grupo de Investigación "Filosofía del Derecho y Derecho Constitucional" adscrito a la Universidad de Cartagena (Colombia). Correo electrónico: luisfernandobermeoalvarez@gmail.com
} 


\title{
RECEPTION OF LUHMANN' SYSTEMS THEORY IN THE COLOMBIAN CONSTITUTIONAL JURISPRUDENCE
}

\begin{abstract}
This paper presents some considerations about the influence that Luhmann's systems theory has had in the decisions of the Colombian Constitutional Court from its inception. It makes a general reference to the basic concepts of the Luhmannian theory, the interrelationship of social systems-law, politics and morals-, and some criticism to legal positivism that might arise from Luhmann. We studied the jurisprudence of the Colombian Constitutional Court from its creation until the research date, analyzing in which of them the Constitutional Court used the Luhmannian theory to support its ruling and how it did it. We found that Luhmann's theory was cited in only three rulings, suggesting its precariousness regarding as a theory "accepted" by law practitioners in Colombia.
\end{abstract}

Keywords:

Autopoiesis; binary code; law; morals; politics; systems.

\section{A RECEPÇÃO DA TEORIA DOS SISTEMAS DE LUHMANN NA JURISPRUDÊNCIA CONSTITUCIONAL COLOMBIANA}

\section{RESUMO}

Este texto apresenta algumas considerações sobre a influência que a teoria dos sistemas de Luhmann teve sobre as decisões do Tribunal Constitucional colombiano desde sua criação. Encontraremos uma menção geral sobre os conceitos básicos da teoria Luhmanniana, sobre a inter-relação dos sistemas sociais Direito, Política e Moral e sobre algumas críticas que poderiam ser apresentadas a partir de Luhmann para o positivismo jurídico. Um estudo da jurisprudência do Tribunal Constitucional colombiano foi feito desde sua criação até a data da investigação, analisando em quais deles o tribunal constitucional utilizou a teoria Luhmanniana para sustentar sua decisão e de que maneira o fez, constatando que apenas em três sentenças citou-se a teoria de Luhmann; isso indica uma precariedade quanto a sua consideração como teoria "aceita" por quem exerce o direito na Colômbia

\section{Palavras-chave:}

Direito; política; moral; sistemas; autopoiese; código binário. 
Y bien, señores del jurado, ¿cuál es su veredicto? - dijo el Rey por enésima vez en aquel día.

— ¡No! ¡No! —le atajó la Reina-. ¡La sentencia primero!... ¡Tiempo habrá para el veredicto!

—Qué insensatez! —exclamo Alicia-. ¿Dónde se ha visto que la sentencia se dicte antes de saber el veredicto? (Carroll, 2013, p. 216)

\section{Introducción}

El campo del derecho es complejo, en él se sintetizan la mayor parte de los problemas sociales, desde conflictos económicos (derecho privado por excelencia), hasta conflictos personales como las libertades religiosas (derecho constitucional). En este contexto, el derecho es como un rey Midas, al decir de Martínez (1999), que vuele jurídico a lo que toca, aunque propiamente no tenga un objeto de acción claramente determinado. No se sabe si el derecho actúa sobre las normas (positivismo jurídico) o sobre la moral (iusnaturalismo). Asumir al derecho como sistema social (Luhmann) implica superar estos paradigmas y ver lo jurídico desde otra óptica. Niklas Luhmann ha planteado el fenómeno jurídico de una forma muy diferente a la tradicional, teniéndolo como un sistema social autopoiético cerrado, que no tiene un fin, sino solo un sentido: determinar lo que es legal y lo que no. Consideramos a este autor fundamental dentro del paradigma neopositivista para la comprensión del fenómeno jurídico más allá de los argumentos clásicos de la tradición de la teoría y filosofía del derecho hasta mediados del siglo xx.

En este sentido, este trabajo presentará el resultado de una pequeña investigación sobre la forma en que se ha recepcionado la Teoría de los Sistemas de Luhmann y su concepción del derecho en la jurisprudencia constitucional colombiana. Para ello, (i) se precisarán algunos puntos teóricos que se consideran centrales en la propuesta de la teoría de los sistemas sobre el derecho. Posteriormente (ii) se analizarán las sentencias de la Corte Constitucional colombiana en las que se ha citado al profesor Luhmann, y, por último, (iii) se realizará un análisis crítico sobre los puntos en común y diferencias entre la sociología del derecho de Luhmann y sus implicaciones a la teoría del derecho positivista, especialmente la de H. L. A. Hart (1963). A continuación, para hacer más clara la exposición al lector, se exhibirán las preguntas guía que han sido objeto de indagación en este trabajo:

1. ¿Cuáles son los planteamientos claves de la teoría de los sistemas de Niklas Luhmann para la comprensión del fenómeno jurídico?

2. ¿Cuál ha sido la recepción de esta teoría en la jurisprudencia constitucional colombiana?

3. ¿Qué criticas podrían plantearse hacia el positivismo jurídico desde la concepción del fenómeno jurídico de la teoría de los sistemas de Luhmann?

Estas preguntas ayudan a precisar el problema objeto de reflexión y, así mismo, los resultados de este análisis. La idea final es analizar la recepción de esta teoría en la jurisprudencia constitucional colombiana, por lo que se espera que este trabajo contribuya al análisis teórico del derecho y su aplicación por parte de los funcionarios. Así mismo, que el estudio aporte a la reflexión sobre la forma en que son utilizadas las teorías sobre el derecho, en las fuentes jurídicas formales del sistema jurídico colombiano.

De esta manera, el estudio que a continuación se presenta plantea una reflexión sobre la forma en que la Corte Constitucional ha utilizado la teoría de los sistemas de Niklas Luhmann en la resolución de tres casos específicos.

\section{A. Conceptos claves para entender la concepción del fenómeno jurídico desde la Teoría de los Sistemas de Luhmann}

La consideración del mundo social como sistema es propiamente luhmanniana, toda vez que 
fue a partir de la teoría de los sistemas que llegó a concebirse un mundo casi completamente ordenado por comunicaciones ${ }^{1}$. Una imagen de mundo según la perspectiva luhmanniana sería tal vez muy cercana a la representación que se hace en la película Matrix (1999) de los hermanos Wachowski, donde el cuerpo está en un lugar, estático, y la mente en otro, dinámica, proyectada hacia su interior en un enjambre de comunicaciones que crean lo que comúnmente se denomina realidad.

Sin embargo, está representación de la consideración del mundo o, mejor, de la sociedad, como "la matrix" sería un tanto simplista. Conviene entonces explicar con mayor detalle los postulados teóricos más importantes para la comprensión de esta teoría en el ámbito jurídico. El concepto de sistema en Luhmann aparece a partir de la comparación entre la estructura celular y la sociedad, en la que la autopoiesis juega el papel fundamental ${ }^{2}$.

Este fenómeno puede ser considerado (a grandes rasgos) como la capacidad de autorreproducción que tiene un sistema. Tal como algunas células, los sistemas sociales se auto-

1 "La sociedad y sus subsistemas, según Luhmann, no se compone de individuos, sino de comunicaciones. La define como 'un sistema de comunicaciones que integra selectivamente el potencial físico, químico, orgánico y psíquico de la humanidad, y la conducción de esa selectividad encuentra su propia realidad y su autonomía como sistema'" (García, 2005, p. 157). En sentido similar: "La sociedad se percibe fragmentada en una multiplicidad de redes comunicativas cerradas [...]. Cada una de estas redes construye una realidad propia, en principio incompatible con las construcciones de la realidad de las otras redes. Al mismo tiempo, la multiplicación y fragmentación de las individualidades se corresponde con una multiplicación y fragmentación de los discursos sociales [...]. Sobre la base de sus códigos y programas específicos, cada red de comunicación especializada produce 'personas' - artefactos semánticos de actores individuales- a las cuales atribuye acciones" (Teubner, 2002, p. 549).

2 "Si los discursos sociales son sistemas autopoiéticos, esto es, sistemas que recursivamente producen sus propios elementos gracias a su propia red de elementos, entonces se basan en la autoreferencialidad" (Teubner, 2002, p. 546). rreproducen, generando sus propios elementos. De este modo, los sistemas son capaces de mantenerse, es decir, de sobrevivir o conservarse, a pesar de lo agreste del medio, de hecho, su contacto con el medio es mínimo.

Bajo esta primera aproximación a la teoría de los sistemas del profesor Niklas Luhmann, se erige su consideración del derecho como un sistema social (autopoiético) cerrado. La especie sistémica de ser "cerrado" la tiene el derecho por su capacidad de producir en mayor medida sus propios elementos, sin requerir demasiado del entorno (medio), en contraste con los sistemas sociales "abiertos", que necesitan interactuar en mayor medida con el entorno. Para el derecho es suficiente reproducirse a partir de su código binario propio ${ }^{3}$.

En este contexto, el derecho funciona siguiendo el código: legal/ilegal ${ }^{4}$, acudiendo al sentido de orden social obligatorio. Este código se

3 Para el profesor Alemán, el derecho funciona como un "sistema jurídico como un contexto de comunicación operacionalmente cerrado $\mathrm{y}$, a la vez, informacionalmente abierto, que se diferencia y delimita mediante sus propias operaciones en un entorno social y, al mismo tiempo, determina en qué aspectos se deja influir por el entorno. El sistema está especificado exclusivamente mediante sus propias estructuras. No hay un derecho que se pudiera introducir desde fuera del sistema y, por otra parte, tampoco un derecho que pudiera ser exportado desde el sistema al entorno. Todas las comunicaciones que son procesadas jurídicamente son procesadas en el sistema, se han de basar en el recurso al Derecho ya existente y, de este modo, contribuyen a la reproducción del Derecho. Pero precisamente porque ello es así el sistema puede reaccionar frente a todas las comunicaciones que puede tratar internamente como problema jurídico - al igual que el cerebro, es, ciertamente, un sistema nervioso operacionalmente cerrado de manera absoluta que, en el nivel de sus propias operaciones, no mantiene ninguna clase de contacto con el entorno, pero que precisamente por ello puede procesar de manera complejísima muy pocas irritaciones (por ejemplo, las fotoquímicas) provenientes de su entorno-" (citado en Luhmann, 2014, p. 41).

4 "El Derecho es un sistema autónomo funcional de la sociedad que determina por sí mismo aquello que regula y que somete todos los supuestos de hecho sobre los que comunica al código binario conforme a De- 
realiza (de acuerdo con el sentido indicado), es decir, el derecho opera a través de comunicaciones. Este punto es sumamente importante en la conceptualización del derecho como sistema ${ }^{5}$ en Luhmann $y$, en general, para toda su teoría de sistemas. Al respecto, conviene explicar algo más sobre el sujeto y el objeto en la consideración de la teoría de sistema luhmanniana.

Puede decirse que, a partir de la modernidad, concretamente del Discurso del método, el conocimiento es fruto de la relación sujetoobservador vs. objeto-observado ${ }^{6}$. En este sentido, el sujeto es el hombre, específicamente la razón, y el objeto es la realidad (exterior). Con este argumento cartesiano se rompió la pretensión epistemológica de la religión ${ }^{7}$; en adelante, todo conocimiento está sujeto a la experimentación.

A su vez, podría decirse que después de los avances científicos de la física (hasta la primera mitad del siglo xx) esta relación "externa" sujeto-objeto cambió radicalmente. Después de la comprobación teórica del principio de incertidumbre de Heisenberg ${ }^{8}$, el conocimiento

recho o contrario a Derecho (Recht/Unrecht)" (Luhmann, 2014, p. 38).

5 "El Derecho determina exclusivamente con referencia a normas jurídicas o a decisiones jurídicas, lo que es Derecho y lo que es contrario a Derecho [...]. La comunicación sobre el Derecho solamente se puede llevar a cabo con referencia a comunicación adicional sobre el Derecho. Si se hace esto y en la medida en que esto se haga, se participa en el sistema jurídico..." (Luhmann, 2014, p. 40).

6 "La noción de sujeto individual que subyace a las anteriores apreciaciones es la del sujeto como conciencia individual pensante que arranca de Descartes y se erige en distintivo de la edad moderna" (García, 2005, p.157).

7 Conocer a Dios, la naturaleza y el universo a partir de la razón, la cual solo debe servir para este fin.

8 "No hay manera de eliminar el observador - nosotros- de nuestra percepción del mundo, creada por nuestro procesamiento sensorial y por la manera de en qué pensamos y razonamos. Nuestra percepción - y por lo tanto las observaciones sobre las cuales se basan nuestras teorías- no es directa, sino más bien está conformada por una especie de lente, a saber, la solo será posible a partir de una síntesis entre sujeto-observador: objeto-observado. Con este argumento inderogable de la física contemporánea, las consideraciones filosóficas sobre el ser y la realidad quedan zanjadas (al menos en parte), prácticamente dando la razón a la hermenéutica9 ${ }^{9}$. A partir de alli deja de existir, por un lado, el ser humano y, por el otro, la realidad (si así se le puede llamar), el mundo, la naturaleza, etc.

Este contexto filosófico científico es en el que Luhmann plantea su teoría, con todas sus implicaciones. Dada esta conjunción entre sujeto=objeto, ya el hombre no puede ser el centro del conocimiento, no está llamado a ser el núcleo de la epistemología. Luego, ¿cómo se puede conocer? Esta pregunta queda sin respuesta en la teoría luhmanniana, teniendo en cuenta que: (i) a partir de estas precisiones toda consideración de conocimiento queda rodeada por la incertidumbre, y (ii) que no es el objeto de la teoría de los sistemas. Sin embargo, para determinar cuál es el sujeto de ordenación de los sistemas sociales, eliminando de entrada al hombre, Luhmann responde que son las comunicaciones. En este sentido, el hombre también será un sistema, por lo que, necesariamente, implicará comunicación. Su definición teórica de ser humano es un sistema psíquico orgánico abierto ${ }^{10}$.

estructura interpretativa de nuestros cerebros humanos" (citado en Hawking y Mlodinow, 2010, p. 55).

9 "El mundo es una construcción de nuestras sensaciones, percepciones y recuerdos. Conviene considerar que existe objetivamente por sí mismo. Pero no se manifiesta, ciertamente, por su mera existencia. Su manifestación está condicionada por acontecimientos especiales que se desarrollan en lugares especiales de este mundo nuestro, es decir por ciertos hechos que tienen lugar en un cerebro" (Schrödinger, 1999, p. 9).

10 Véase Luhmann (2013, pp. 38-39). En este punto coincide el profesor Carlos Orozco (2014) sobre la conceptualización del sujeto que hace Luhmann como "subsistema psico-físico" (p. 105). 


\section{El Derecho, la Política y la Moral, como sistemas sociales autopoiéticos}

Un sistema se convierte en autorreferente cuando ha evolucionado sistémicamente (Mejía, 2005, pp. 210); en este contexto, el derecho ha evolucionado ${ }^{11}$ hasta convertirse en un sistema cerrado que se comunica con su entorno bajo su código binario legal/ilegal, y que cuenta con unos elementos propios del sistema que además se autorreproducen creando otros elementos ${ }^{12}$.

El cierre del sistema Derecho hace referencia a la reproducción de sus elementos, instituciones y estructuras, es decir que cualquier comunicación bajo el código legal/ilegal es una comunicación jurídica. Cada elemento del sistema traspasa validez normativa a otros elementos del sistema, por ello en el sistema Derecho no existe jerarquía normativa, sino que las leyes y normas judiciales se encuentran en posiciones asimétricas (Mejía, 2005, pp. 200-201). En términos de Luhmann, el símbolo del sistema Derecho se traduce en la validez jurídica, es el símbolo que reproduce la unidad del sistema dentro de su operación (Luhmann, 2009, p. 154$)^{13}$.

La validez no es una norma ni una norma fundamental ni una metanorma. En el sistema Derecho se tiene o no se tiene validez; sin embargo, en concordancia con la autorreproducción del sistema, los elementos válidos se pueden modificar en no válidos. Esta modifi-

11 "la positivización del derecho, una conquista evolutiva que, tras numerosos intentos anteriores, solo se hizo plenamente efectiva en las modernas sociedades industriales" (Luhmann, 2013, p. 55).

12 "Como sistemas autopoiéticos [...] no pueden sino producir regularidades que se regulan a sí mismas y que gobiernan la transformación de sus propias regularidades" (Teubner, 2002, pp. 546-547).

13 En sentido similar se refiere Teubner (2002): "La aplicación recursiva de las operaciones a los resultados de estas mismas operaciones no conduce necesariamente al bloque paradójico de la paradoja o a la mera arbitrariedad, sino que, bajo ciertas condiciones, conduce a que surjan los valores propios (Eigenvalues)" (p. 547). cación se realiza a través de un procedimiento que limita y regula cómo se puede llegar a esa validez, lo que nos permite concluir que si bien la validez no es una norma como ya se mencionó, sí se constituye en una forma (Luhmann, 2009, p. 160).

La validez reacciona a la dinámica propia del sistema y se hace indispensable cuando el sistema ya puede modificarse a sí mismo, cuando ya es un sistema autorreferente. La validez (el procedimiento) cualifica las normas en válidas o no válidas. La norma no puede ser más válida o menos válida; por eso las fuentes del derecho a las que aluden los teóricos del positivismo no tienen cabida según Luhmann, toda vez que no puede hablarse de jerarquía normativa sino de asimetría (Luhmann, 2009, pp. 161-162).

En conclusión, el derecho no puede operar bajo una norma inválida, la norma inválida se traduce en no derecho, está por fuera del sistema, la invalidez es solo un punto de referencia, válido/no válido, derecho/no derecho ${ }^{14}$.

Ahora bien, no toda comunicación jurídica transporta validez; no son válidas o inválidas las notificaciones de las pretensiones jurídicas; son válidas si las decisiones jurídicas aplicables también lo son, no solo las decisiones de jueces y legisladores sino las corporaciones y contratos que afectan y modifican situaciones jurídi-

14 Para Luhmann (2009), "La forma validez/invalidez se distingue también del código derecho/no derecho, que también está estructurado de forma positiva/negativa. Por eso este código puede prever lo que no conforme a derecho (injusticia) tenga consecuencias jurídicas: castigos, responsabilidad por daños causados, ineficiencia jurídica de determinadas acciones. También los presos tienen derechos que pueden hacer valer en caso dado. Por lo demás, todo el mundo tiene derecho a que se determine de manera jurídica el hecho de qué actúa de manera ilegal. Por lo tanto, para cruzar de un lado a otro - cruzar el límite- del código derecho/no derecho, se requiere del símbolo de la validez. Las posibilidades de enlace se producen en relación con el derecho válido; tanto para determinar acciones particulares en calidad de jurídicas, como para el caso contrario de la antijuridicidad" (p. 163). 
cas, como el testamento. La validez se traduce en las operaciones que efectúan las autopoiesis del sistema y sin las cuales no sería posible la diferenciación de un sistema jurídico, clausurado operativamente (Luhmann, 2009, p. 164).

Así las cosas, el sistema Derecho está cerrado normativamente y abierto cognitivamente, lo que quiere decir que no puede importar normas de otros sistemas, pero sí puede tomar referencias de otros sistemas que convierte en normas jurídicas para introducirlas al sistema (Mejía, 2005, p. 202). Por otro lado, el sistema Política, para Luhmann, también es un sistema autorreferente; se produce y reproduce por sí mismo a través de sus elementos, que para el caso son decisiones políticas, comunicándose bajo el código binario gobierno/oposición.

Según Luhmann, el sistema Política y el sistema Derecho comparten una característica similar por excelencia: su autopoiesis; adicionalmente, el sistema Política, haciendo uso de su código propio poder, puede utilizar el código jurídico conjugando su propio código (poder legal/poder ilegal). Así mismo, el sistema Política suministra al sistema Derecho el derecho positivo, y el sistema Derecho le suministra al sistema Política la cobertura para la materialización del poder, lo que implica que el sistema Política hace uso del código jurídico como un subcódigo para estructurar el ejercicio del poder. Es así como los sistemas sociales Política y Derecho, al compartir el mismo tipo de estructuras, sufren una interpenetración, una dependencia recíproca entre los sistemas que hace difícil en ocasiones la operatividad cerrada de cada uno (Mejía, 2005, p. 211).

Otra interrelación que presenta Luhmann entre los sistemas Política y Derecho es que el sistema Política es dependiente del sistema Derecho que produzca el sistema jurídico, pero con ello no quiere decir que los elementos del sistema Derecho se introduzcan en el sistema Política, sino que Luhmann contempla para este caso el derecho como un mero instrumento (Mejía, 2005, p. 212).
Del mismo modo, según Luhmann, entre los sistemas Política y Derecho con alta frecuencia se da lo que el autor denomina acoplamiento o conexión estructural. En términos de Luhmann, cuando se da un acoplamiento estructural entre dos sistemas, esto no quiere significar una especie de fusión o amalgamiento entre ellos, sino que existe una coordinación estable entre las operaciones de cada uno por momentos (Baraldi, Corsi y Espósito, 1996, pp.19-21).

En este sentido, un elemento del sistema jurídico puede ser al mismo tiempo un elemento del sistema Política en un mismo acto de comunicación, los cuales se separarán inmediatamente después de la conexión, sin que por esta eventualidad exista una coincidencia en los procedimientos de cada uno de los sistemas.

El tercer sistema que nos ocupa en este análisis es el sistema Moral, entendiendo como moral, según Luhmann, un concepto generalizado, no subjetivizado, que pueda ser demostrable empíricamente y que se comunique bajo un código específico. Lo que constituye la autorreferencialidad del sistema Moral es la ausencia de la misma en otros sistemas, siendo entonces Moral un sistema autónomo que no interviene en el código de otros sistemas ni es intervenido (Mejía, 2005, p. 213).

El código binario bajo el que se autorreproduce el sistema Moral es bueno/malo, resaltando que ningún sistema puede aplicarse a sí mismo su código binario, es decir, no nos podemos preguntar si el derecho es legal o ilegal, o si la moral es buena o mala, porque esto constituye una paradoja que puede inmovilizar el sistema en su comunicación. El papel de la ética, entonces, dentro del sistema, es la descripción de la moral, sin inclinarse hacia ninguno de los dos extremos del código binario (Mejía, 2005, p. 214).

En sintesis, la legitimidad política y la justificación moral son externas al sistema Derecho y no tienen significancia para este, pues, como 
ya se explicó, en el derecho, los factores de eficacia y legitimidad se subsumen en la validez como unidad del sistema. En este sentido, el ordenamiento jurídico y el sistema político no requieren justificación moral alguna. Moral, Política y Derecho son tres sistemas sociales independientes, autorreferentes, que lo que hacen es interconectarse o comunicarse a través de sus códigos binarios, pero sin que ninguno se introduzca en el otro, lo cual deviene una importante conclusión: el derecho reduce complejidad creando expectativas de comportamiento desprovistas de fundamento moral $e$ ideológico. El derecho válido se crea desde el derecho, sin fundamentaciones morales o políticas (Mejía, 2005, p. 215).

Para finalizar este breve resumen sobre los supuestos teóricos de la teoría de los sistemas Luhmann con relación a su concepción del derecho, resulta necesario exponer una cita que se considera importante para sintetizar la concepción del derecho y la función judicial en Luhmann:

El derecho positivo es hoy concebido como un sistema de normas que se lleva a cabo a través de la decisión y que puede ser cambiado a través de la decisión. En los procesos decisorios en que se imparte justicia tiene lugar un aprendizaje [...] que adapta el derecho a la evolución de la sociedad. (Luhmann, 2013, p. 55)

\section{B. La recepción de la teoría de los sistemas de Luhmann en la jurisprudencia constitucional colombiana}

Para dar respuesta a esta pregunta realizamos una búsqueda de las sentencias de la Corte Constitucional Colombiana en las que se citara expresamente al autor bajo análisis, desde la creación de la Corte hasta la fecha. El resultado de la pesquisa fueron tres sentencias, en las cuales se menciona el autor en el salvamento de voto de dos de ellas, sin que se haga mención del mismo en el cuerpo de la providencia, y una tercera, en la cual sí se menciona a Luhmann en la parte considerativa, pero a manera de pie de página, citando una de sus obras.

Evidenciadas las providencias mencionadas, se analizaron los problemas jurídicos planteados en cada sentencia y la forma en que fue utilizada la teoría de Niklas Luhmann en la argumentación de la Corte Constitucional, con el fin de determinar si la jurisprudencia constitucional colombiana utilizó la teoría de los sistemas de Luhmann en su consideración sobre el Derecho.

De las tres sentencias analizadas, escogimos una en la que se puede evidenciar claramente la influencia de la teoría luhmanniana en las consideraciones de los magistrados que salvaron el voto: la sentencia C-319 de 1996, con magistrado ponente Vladimiro Naranjo Mesa, que mencionaremos en tercer lugar. Sobre las dos restantes se hará una alusión general, pues la mención que se hace de la teoría estudiada no representa, a nuestro juicio, una aplicación coherente u oportuna de la misma.

La primera de las sentencias que conforman la muestra analizada es la sentencia de tutela T-539A de 1993, con magistrado ponente Carlos Gaviria Díaz, en la cual se plantea como problema jurídico un conflicto de derechos entre la libertad de cultos consagrada en el artículo 19 de la Carta y la autonomía universitaria establecida en el artículo 69. Al tomar la decisión sobre la violación del derecho a la libertad de cultos de la accionante, la Corte considera que no se trata, pues, de un conflicto entre dos derechos consagrados en la Carta (la libertad de cultos y la autonomía universitaria) que deba desatar el fallador asignando una jerarquía más alta a alguno de ellos, sino de la verificación de que la universidad está actuando dentro de la más rigurosa órbita de juridicidad, que no está violando ni amenazando violar el derecho fundamental de nadie $y$, por ende, que la tutela invocada no es procedente. 
En este caso, el magistrado Eduardo Cifuentes Muñoz, quien salva el voto, fundamenta su argumento en que la objetividad del derecho hace más seguro al sistema, pero afecta la comunicación entre el derecho y la realidad, afirmando que la justicia del caso satisface las necesidades sociales de justicia, pero hace inseguro y aleatorio el sistema, por lo que es necesario encontrar un punto intermedio en el cual beneficios y desventajas encuentren su mejor combinación.

Indica el magistrado Cifuentes, en su salvamento de voto, que esta preocupación por la tensión entre estos valores derecho/realidad, ha sido explicada en detalle por Niklas Luhmann. Cita textualmente:

De acuerdo con el sentido de esta tensión del sistema jurídico, se puede extraer una regla según la cual toda solución que consulte la justicia del caso debe ser introducida siempre y cuando la afectación que se ocasione al funcionamiento predecible $y$ seguro del sistema sea mínima. Ni la objetividad del derecho ni la solución justa del caso concreto son fines absolutos que puedan ser aplicados con independencia de otros valores y principios. Negarse a la introducción de una excepción cuya aplicación no afecta de manera apreciable el buen funcionamiento institucional, la objetividad del derecho y la seguridad jurídica, es una manera de razonar empecinada en la protección de formas jurídicas insulsas y contrarias al estado social de derecho. (T539A/1993)

Sin embargo, no es claro al manifestar si lo anterior se trata de una cita del profesor Luhmann o es el extracto de alguna de sus obras, o si es una conclusión propia.

En segundo lugar, tenemos la sentencia de tutela T-885 de 2014, con magistrado ponente Gloria Estella Ortiz Delgado, relacionada con la demora en el pago de un subsidio de vivien- da, cuyo problema jurídico consiste en si las entidades accionadas han vulnerado al actor su derecho fundamental a la vivienda digna, por la falta de adjudicación del subsidio de vivienda para población desplazada, al que se postuló y se encuentra en estado de "calificado" desde el año 2007.

Sobre el particular, la Corte Constitucional argumenta en sus consideraciones que la calificación en la asignación de los subsidios, según lo expresan las entidades accionadas, no implica la existencia de "turnos" de asignación conforme a lo visto. Sin embargo, la calificación sí es un referente cuantitativo para la adjudicación de los subsidios, basado en el puntaje de cada postulado, que genera una expectativa normativa a los hogares en condición de desplazamiento que participan de la política pública. Con relación a la palabra 'expectativa' encontramos la siguiente cita al pie de página:

Para Luhmann "Las expectativas normativas terminan por limitar el ámbito de conductas posibles generando así una base de confianza que, a pesar de las incertidumbres futuras, permita tomar decisiones presentes" en Luhmann N, La paradoja de los derechos humanos, Universidad Externado de Colombia, Bogotá, 2014 pág. 21. (T-885/2014)

Al respecto no encontramos una relación directa entre la semántica de la palabra 'expectativa' como sinónimo de posibilidad o perspectiva, como lo USA la Corte, con el significado del término 'expectativa' en la teoría luhmanniana, que ya hemos abordado en este trabajo.

En tercer lugar, encontramos la sentencia C-319 de 1996, con magistrado ponente Vladimiro Naranjo Mesa, como ya mencionamos, dentro de la cual, el problema jurídico a resolver es si la norma acusada, artículo 148 del Código Penal, subrogado por el artículo 26 de 
la ley 190 de $1995^{15}$, viola o desconoce las garantías sustanciales o procesales contenidas en la Constitución. Sobre el particular cabe aclarar que la norma acusada ya no está vigente, pero el nuevo artículo que describe el tipo penal lo hace en los mismos términos demandados ${ }^{16}$.

Para el caso concreto, el actor considera que el término "no justificado", previsto en la norma demandada, es violatorio del derecho al debido proceso, contenido en el artículo 29 de la Constitución Política, toda vez que, según él, traslada la carga de la prueba a quien no le corresponde probar nada dentro del proceso penal, es decir, al sindicado.

La Corte Constitucional declara exequible el articulado, toda vez que el delito de enriquecimiento ilícito de los servidores públicos, tiene un claro origen constitucional que se refleja en el interés que le asiste al Estado no solo de legitimar la adquisición de la propiedad, sino además de sanear la administración pública, cuyo patrimonio se ve afectado por la conducta indebida de aquellos servidores que, por el ejercicio de su cargo, incrementan de manera injustificada su propio peculio con grave detrimento de la moral social.

15 El texto de la norma acusada es: "Artículo 148. El empleado oficial que por razón del cargo o de sus funciones, obtenga incremento patrimonial no justificado, siempre que el hecho no constituya otro delito, incurrirá en prisión de dos (2) a ocho (8) años, multa equivalente al valor del enriquecimiento e interdicción de derechos y funciones públicas por el mismo término de la pena principal".

16 El texto del artículo vigente es: "Artículo 412 de la Ley 599 de 2000. Enriquecimiento ilícito. Modificado por el art. 29, Ley 1474 de 2011, Modificado por el art. 33, Ley 1474 de 2011. El servidor público que durante su vinculación con la administración, o quien haya desempeñado funciones públicas y en los dos años siguientes a su desvinculación, obtenga, para sí o para otro, incremento patrimonial injustificado, siempre que la conducta no constituya otro delito, incurrirá en prisión de seis (6) a diez (10) años, multa equivalente al doble del valor del enriquecimiento sin que supere el equivalente a cincuenta mil (50.000) salarios mínimos legales mensuales vigentes, e inhabilitación para el ejercicio de derechos y funciones públicas de seis (6) a diez (10) años".
Entre otros argumentos adicionales, afirma la Corte que el conocimiento que tenga el Estado sobre los bienes y rentas de los servidores públicos, antes que una carga, constituye un principio que debe gobernar sus actuaciones (art. 209 de la C.P.) y con ello se pretende proteger la función pública $y$, en particular, la moral social, aclarando que nadie está obligado a ejercer una función pública. Se trata de una labor en la que los ciudadanos deciden participar libremente; pero, al aceptarla, están asumiendo no solo las cargas y responsabilidades que se deriven del ejercicio del cargo, sino que, además, se están colocando en una situación permanente de exigibilidad por parte del Estado, en lo que se refiere al monto y manejo de sus bienes.

Sobre el particular, los magistrados Carlos Gaviria Díaz y Alejandro Martínez Caballero se apartan respetuosamente de la decisión mayoritaria, en cuanto a su fundamento, mas no de la decisión de la honorable Corte, esgrimiendo principalmente que el argumento para declarar exequible el artículo demandado no se puede buscar por fuera del derecho, haciendo énfasis en que a pesar de que siempre ha existido la tensión entre política criminal y derecho fundamental, la razón que justifica la política criminal debe estar dada en la dogmática jurídico penal y no en otras esferas sociales como la moral.

La Corte argumenta que el hecho de que los bienes y rentas del servidor público deben ser de conocimiento del Estado es un deber constitucional, con el fin de proteger la función pública, y es un deber moral, salvaguardando la moral social; afirmación sobre la cual se presentan en total desacuerdo los magistrados que salvan el voto, toda vez que de ninguna manera la moral debe ser la justificación de la política criminal, sino el derecho.

Resaltan Gaviria y Martínez que en Colombia hemos tendido a basar la política criminal en valoraciones empíricas relacionadas con momentos políticos coyunturales particulares, sobre todo reactivos, y no en la dogmática penal. 
De esta manera, el derecho penal termina resolviendo problemas que no le corresponden, lo que se traduce en la instrumentalización del derecho penal para intereses políticos coyunturales; situación que se exacerba si el juez constitucional confunde moral con derecho o política criminal con política.

Para el caso concreto, aclaran los magistrados que el error interpretativo del artículo 34 de la Carta Política ${ }^{17}$ reside en la falsa idealización de la "moral social" a la cual alude la disposición; el error se concreta en "moral social" como un bien jurídico supuestamente tutelado por el enriquecimiento ilícito, cuando la misma Corte se ha pronunciado aclarando que se trata de una alusión a la función instrumental del enriquecimiento ilícito. El bien jurídico "moral social" no existe en el orden jurídico.

De este modo, indican los autores del salvamento de voto aludido, la Corte le da a la moral social efectos sobre la función punitiva estatal, y la convierte en un bien jurídico supuestamente tutelado por el enriquecimiento ilícito, dando a entender que lo injustificado de un patrimonio no es evaluado como un elemento de antijuridicidad que puede invadir la esfera de la tipicidad, o simplemente como un elemento de tipicidad, sino que es transferido al universo de las leyes éticas.

Finalizan su intervención resaltando que la corrupción no es un asunto que deba resolver la justicia, haciendo hincapié en que exigir al sistema del derecho y, más aún, exigir del sistema del derecho penal, una respuesta radical de justicia general entraña el riesgo de la ineficacia y la decepción.

17 Artículo 34 C.P.: "Se prohíben las penas de destiero, prisión perpetua y confiscación. No obstante, por sentencia judicial, se declarará extinguido el dominio sobre los bienes adquiridos mediante enriquecimiento ilícito, en perjuicio del Tesoro Público o con grave deterioro de la moral social".
Ahora bien, al momento de relacionar los argumentos del salvamento de voto con la teoría de Niklas Luhmann, se establece en el mismo salvamento que mientras el sistema "política" pretenda invadir el sistema "derecho", el sistema Derecho no podrá ofrecer justicia. El sistema del derecho, o un subsistema del mismo, como es el derecho penal, están incapacitados para ofrecer justicia, si en su funcionamiento es invadido por la política. En este mismo sentido, resaltan los autores del salvamento, que cuando dentro del sistema del derecho se recurre a elementos de otro sistema como la "moral social" se niega el sistema, se neutraliza su función, pues se bloquea con elementos extraños que aquel (el sistema Derecho) no reconoce y no logra procesar.

Parafraseando a Luhmann, los magistrados en cuestión aluden que la moral, el derecho y la política son sistemas autodiferenciados, cada uno de ellos respecto de los demás. Ninguno constituye el centro de la sociedad y cada cual debe "reducir complejidad"; es decir, tematizar y resolver los dilemas y problemas que se le plantean, por lo que toda confusión de ámbitos y toda invasión de un sistema a otro causa trastornos e involuciones que repercuten negativamente sobre el funcionamiento de toda la sociedad en conjunto.

Con todo, como conclusión del análisis de la sentencia descrita, y dando respuesta a la pregunta que hoy nos ocupa, consideramos que la teoría de los sistemas de Luhmann, con relación al derecho, ha sido recibida en la jurisprudencia constitucional colombiana de manera precaria, teniendo consideraciones especialmente en salvamentos de votos y solo como un híbrido creativo en una sola sentencia, que es la última a la que hacemos alusión.

En el salvamento de voto que hemos analizado, encontramos un ejemplo claro y preciso de la aplicación de la teoría de los sistemas sociales de Luhmann, en el ordenamiento jurídico colombiano. Observamos cómo, desde la teoría de los sistemas, encontramos una fundamen- 
tación lógica sobre los problemas de nuestra realidad social, cuando pretendemos mezclar los elementos del derecho con la política; o cuando pretendemos fundamentar las normas jurídicas en la moral o la ética.

Tal y como lo describen los magistrados en el salvamento de voto, no es posible que nuestra legislación esté basada en elementos vagos o difusos, como la moral o los valores, el ethos. Tampoco es válido pretender solucionar los problemas atenientes al sistema Política, como es la corrupción de los servidores públicos, con elementos del sistema Derecho. Cuando el legislador busca con su articulado solucionar con el derecho problemas morales o políticos, el derecho no responde, simplemente porque dentro de su codificación, dentro de sus elementos, estructuras e instituciones no encuentra la salida sobre asuntos que no le competen ni le corresponden.

Como consecuencia de la intervención del sistema Moral en el sistema Derecho, tendríamos que preguntarnos, entonces, si es válido penalizar a un servidor público que no justifique un incremento en sus bienes y rentas, por el hecho de que afecta la moral social de los demás, ofende a los ciudadanos, es un acto "mal visto"; para luego preguntarle a cada uno de los ciudadanos si en realidad se siente ofendido o no y, con base en ello, emitir un juicio.

Esta es la manera como el sistema Derecho se vuelve ineficaz o, en términos del observador externo, se vuelve injusto.

\section{Breves críticas sobre el positivismo jurídico desde la teoría de los sistemas}

El propósito de este acápite es realizar unas breves consideraciones sobre los aportes que hizo la teoría de los sistemas de Luhmann frente al desarrollo del positivismo jurídico en sentido estricto. Para esto, se analizarán algunos planteamientos enfrentados entre la teoría del derecho luhmanniana y la hartiana ${ }^{18}$. Teniendo en cuenta que se ha hecho previamente una aproximación a la teoría de los sistemas de Luhmann y sus planteamientos sobre el derecho, es importante hacer algo similar con relación a la teoría del derecho de Hart, para luego poder hacer el análisis de sus argumentos diferenciados.

\section{Sobre la regla de reconocimiento}

Quizás el mayor aporte de Hart a la teoría del derecho de corte positivista haya sido la introducción del concepto de "regla de reconocimiento" para superar la contradicción lógica a la que llegó la Teoría pura del Derecho de Kelsen.

En este contexto, para el positivismo jurídico una norma jurídica será jurídica siempre y cuando pertenezca a un sistema jurídico; sin embargo, ¿cómo saber que existe un sistema jurídico? De esta concepción se desprenden varios problemas, pues puede conllevar a un círculo vicioso, toda vez que ha de ser una primera norma (P1-Permisiva o Facultativa) la que autorice la existencia (vigencia o promulgación) de una segunda norma (P2-de cualquier índole), luego, ¿cuál es el criterio de existencia de la norma P1? ¿Otra norma de este tipo? Y, en este sentido, ¿un regreso a P1 ad infinitum?

Para Hart el criterio fundamental de existencia de un sistema jurídico $y$, por ende, de las normas jurídicas pertenecientes a este sistema es la regla de reconocimiento. En este sentido, esta es secundaria, la cual "especificará alguna característica o características cuya posesión por una regla sugerida es considerada como una indicación afirmativa indiscutible de que se trata de una regla del grupo, que ha de ser

18 La obra El concepto de Derecho de Hart se considera una superación del positivismo jurídico hasta Kelsen, que había sido el punto culminante de esta teoría hasta mediados del siglo xx. 
sustentada por la presión social que esta ejerce" (Hart, 1963, p. 117). Ahora bien, ¿quién determina la regla de reconocimiento? En este punto se distingue entre lo que los funcionarios consideran como normas jurídicas aplicables y lo que los ciudadanos comunes entienden como derecho. Mientras los primeros son los que fijan los significados de las disposiciones normativas, creando las normas propiamente dichas y construyendo el sistema jurídico, los segundos aportan convenciones al sistema Derecho, pero no determinan las normas jurídicas. En últimas, no importa lo que un ciudadano conciba como derecho (subjetivo) o deber (jurídico), hasta que sea determinado así por algún funcionario con capacidad de producir normas jurídicas. Quienes por lo general definen estas normas son los jueces ${ }^{19}$.

\section{Puntos comunes y desacuerdos centrales}

Este aspecto es coincidente con el núcleo de la visión del derecho y la función judicial de en Luhmann. Sin embargo, en la teoría de los sistemas no se tiene en cuenta este concepto de regla de reconocimiento que tanto ha dado de qué hablar en el ámbito jurídico.

Una observación que podría hacerse frente a lo anterior es la finalidad de cada teoría, toda vez que, a pesar de que ambas pueden considerarse como descriptivas, la una (sistemas) está pensando en describir toda la sociedad, y al derecho como un sistema específico de esa sociedad, mientras que la otra (concepto de derecho) está apuntando a resolver la contradicción en la que había dejado Kelsen al derecho y caracterizarlo de forma más "ajustada a la realidad". Esta diferenciación se concreta en la forma de concebir el derecho frente a la sociedad.

19 "el derecho de una determinada sociedad es, en parte, lo que los juristas (en especial, los jueces) creen que es" (Vilajosana, 2010, p. 204).
Mientras que para Hart el derecho es eminentemente social, para Luhmann, si bien el derecho está en la sociedad, no se subordina a ella (como puede interpretarse de la teoría hartiana), sino que este subordina a la sociedad, en el marco de la autorreproducción de su código binario (Luhmann, 2013, pp. 55-56). Por otra parte, si bien para Hart la relación entre derecho moral es contingente, para Luhmann la moral en ningún modo debe mezclarse con el derecho. Por lo que es posible identificar una diferencia de aspectos descriptivos y prescriptivos entre estos dos autores en cuanto a la relación entre derecho y moral. En este contexto, resulta evidente que para ambos existe una relación entre estos dos sistemas; sin embargo, para Hart esta observación resulta necesaria, es decir que no se puede evitar, aunque el resultado de esta relación sea contingente, mientras que para Luhmann esta relación se debe evitar para no bloquear el sistema Derecho.

Teniendo en cuenta todo lo anterior, la crítica fundamental $y$, en este sentido, el aporte fundamental que hizo Luhmann, y que se ha considerado en este trabajo, al positivismo jurídico $y$ al derecho mismo, es descubrir la inevitable tautología en que incurre el derecho a la hora de funcionar, bien sea operando en la sociedad o tratando de definirse a sí mismo ${ }^{20}$.

\section{Conclusiones}

La teoría de los sistemas de Luhmann impactó en el ámbito académico de la segunda mitad del siglo xx. Esta teoría quiso, de alguna forma, abarcar una compresión universalista de la vida en sociedad. En este contexto también se refirió al derecho, aportando algunos rasgos claves para el entendimiento de este fenómeno de forma más precisa y sincera, asumiendo

20 "El Derecho se ve obligado a producir una realidad jurídica autónoma, no pudiendo al mismo tiempo autoinmunizarse a sí mismo frente a las conflictivas realidades producidas por otros discursos sociales" (Teubner, 2002, p. 559). 
su problematización como un rasgo distintivo e inevitable.

En Colombia, esta teoría también fue objeto de utilización por parte de la Corte Constitucional para fundamentar algunas posiciones y conceptos específicos sobre temas concretos. Así las cosas, en tres sentencias de esta corporación fue citada la teoría de Luhmann, lo que indica una precariedad en cuanto a su consideración como una teoría "aceptada" por quienes hacen el derecho en Colombia.

Tal como se mostró, en dos de las tres sentencias se refirieron a Luhmann para apoyar puntos de vista derrotados en las decisiones de la Corte, y solo en una sentencia la teoría formó parte de la estructura del fallo que hizo tránsito de cosa juzgada material (definitiva). Por otra parte, en esta última sentencia hubo una cita absolutamente descontextualizada sobre el concepto de expectativa en el derecho para Luhmann. Mientras para este las expectativas son un elemento integral (conceptual) de toda norma, especialmente de la jurídica, la Corte se refirió a estas como un aspecto a considerar en el marco de un derecho subjetivo de un ciudadano, lo que simplifica muchísimo este concepto. Para Luhmann el carácter esencial de las expectativas es su papel dentro de la decisión judicial, como una reafirmación del sistema Derecho, ya sean cumplidas o defraudadas (Luhmann, 2013, pp. 55-56), no simplemente como una forma de garantizar previamente la declaratoria favorable de un derecho subjetivo.

Así mismo, encontramos una tercera sentencia, en la que sí pudimos evidenciar en el salvamento de voto la influencia de la teoría de Luhmann, de una manera precisa y coherente con los argumentos que lo fundamentan. En sintesis, en este salvamento de voto encontramos la descripción sobre cómo se bloquea el sistema Derecho, cuando se pretende que por medio de este se solucionen problemáticas propias de otros sistemas, como del sistema Política. Vemos también, cómo se vuelve ineficaz el sistema Derecho cuando las decisiones judiciales que lo componen se fundamentan en situaciones morales o éticas.

Por último, se considera que entre los mayores aportes de esta teoría a la comprensión del derecho está, por una parte, la asunción de la tautología como el rasgo fundamental en toda conceptualización del derecho y, por otra parte, la forma necesaria de autoproducirse y diferenciarse de otros sistemas o discursos sociales, como la moral y la política, para superar así las consideraciones de un derecho natural (Luhmann, 2013, pp. 29-33). Mientras que el positivismo jurídico trata de diferenciarse de estos sistemas sociales a través de un concepto único, trascendental y majestuoso, la teoría de los sistemas lo plantea como algo necesario y funcional, no en términos de pureza o de deber, sino de reproducción. En definitiva, se considera que una y otra teoría coinciden en el núcleo central del derecho, que es la validez, y que se replica en todas sus dimensiones; sin embargo, se distingue la teoría de los sistemas en que esta validez es necesaria como forma de ser del derecho, pero puede ser contingente en cuanto a su determinación, es decir, en cuanto al contenido material de las normas, ya sean sustanciales o procedimentales ${ }^{21}$. De ahí que se entienda por qué, bajo la concepción luhmanniana del derecho, la sentencia tenga que venir, aunque eventualmente pueda venir, antes del veredicto ${ }^{22}, \mathrm{y}$ tal vez pueda ser legítimo que se ordene que a alguien: "i[...]le corten la cabeza!"23.

21 Lo que abre la puerta a las críticas profundas a esta teoría. Cabe mencionar la impactante pregunta que hiciera Gadamer (2004) sobre esta teoría en general: "¿usted no creerá sinceramente que Luhmann sostenía todas esas cosas en serio?” (p. 49).

22 El procedimiento de decisión judicial que consiste en que primero se dicta el veredicto y posteriormente se profiere la sentencia es propio del sistema anglosajón, de donde proviene la alegoría a Lewis Carrol.

23 Es tal vez la expresión más repetida por el personaje de la Reina de Corazones en Alicia en el país de las Maravillas. 


\section{Referencias}

Asamblea Nacional Constituyente. (1991). Constitución Política de Colombia.

Baraldi, C., Corsi, G., y Espósito, E. (1996). Acoplamiento estructural. Glosario sobre la teoría social de Niklas Luhmann. México, D. F.: Universidad IberoamericanaITESO/Anthropos.

Carroll, L. (2013). Alicia en el país de las Maravillas. Madrid: Ediciones Cátedra.

Corte Constitucional. (1993). Sentencia T539A. M.P.: Carlos Gaviria Díaz, 22 de noviembre.

— (1996). Sentencia C-316. M.P.: Vladimiro Naranjo Mesa, 18 de julio.

—. (2014). Sentencia T-885. M.P.: Gloria Stella Ortiz Delgado, 20 de noviembre.

Gadamer, H. (2004). Hermenéutica de la Modernidad. Conversaciones con Silvio Vietta. Madrid: Trotta.

García, J. (2005). La filosofía del Derecho de Habermas y Luhmann. Bogotá: Universidad Externado de Colombia.

Hart, H. L. A. (1963). El Concepto de Derecho. Buenos Aires: Abeledo-Perrot.

Hawking, S., y Mlodinow, L. (2010). El gran diseño. Barcelona: Crítica.

Ley 190. 1995. [Congreso de la República de Colombia]. Por la cual se dictan normas tendientes a preservar la moralidad en la Administración Pública y se fijan disposiciones con el fin de erradicar la corrupción administrativa. Diario Oficial 41.878, 6 de junio.

Ley 599 de 2000. [Congreso de la República de Colombia]. Por la cual se expide el código penal. Diario Oficial 44.097, 24 de julio.
Ley 1474. (2011). [Congreso de la República de Colombia]. Por la cual se dictan normas orientadas a fortalecer los mecanismos de prevención, investigación y sanción de actos de corrupción y la efectividad del control de la gestión pública. Diario Oficial 48.181, 12 de julio.

Luhmann, N. (2014 [1988]). Dos caras del Estado de Derecho. En Luhmann, N. La paradoja de los derechos humanos. Tres escritos sobre política, derecho y derechos humanos. Bogotá: Universidad Externado de Colombia.

-. (2009). El derecho de la sociedad. México, D. F.: Herder.

- (2013). La moral de la sociedad. Madrid: Trotta.

Martínez, J. (1999). La imaginación jurídica. Madrid: Taurus.

Mejía, O. (2005). Teoría política, democracia radical y filosofía del derecho. Bogotá: Editorial Temis.

Orozco, C. (2014). Inconvenientes en la recensión de la sociología el derecho de Luhmann. En: Martínez, A. (Ed.), Aportaciones de Niklas Luhmann a la compresión de la sociedad contemporánea (pp. 101-142.). Barranquilla: Universidad del Norte.

Schrödinger, E. (1999). Mente y Materia. Barcelona: Tusquets editores.

Teubner, G. (2002). El Derecho como sujeto epistémico. Hacia una epistemología constructivista del Derecho. Doxa, 25, 533-571.

Vilajosana, J. (2010). El derecho en acción. La dimensión social de las normas jurídicas. Madrid: Marcial Pons. 